\section{Commentary: Don't forget what we are competing for}

\author{
Anthony Estrera, MD, FACS
}

There is no denying the poor late outcomes from unrepaired thoracoabdominal aortic aneurysms (TAAAs), but the treatment, whether open or endovascular, is not benign. Even in specialized centers, the early results remain significant, with mortality ranging from $5 \%$ to $10 \%$ and major, lifealtering morbidity as high as $30 \%{ }^{1-5}$ Although much has been accomplished over the past 30 years in the treatment of TAAAs, there remains room for improvement. It is for this reason that endovascular approaches have risen to the forefront for treatment of TAAAs, providing a lessinvasive approach with comparable early results to open repair.

For abdominal aortic aneurysms, many randomized, controlled trials have pitted open and endovascular aortic repairs, demonstrating early benefits for endovascular over open with similar long-term survival. ${ }^{6}$ It was for this reason that a dramatic shift toward the use of endovascular aortic repair over open occurred across the world. A similar trend has been observed with TAAA repair, but with little evidence to support one method over the other. Since TAAAs occur much less frequently and are more anatomically complex than the infrarenal abdominal aortic aneurysms, aortic centers have gravitated toward specializing in one approach versus the other. This has led to difficulties in providing legitimate "head-to-head" comparisons for appropriate statistical analysis.

The group from Toronto is to be commended for providing more information on this topic, since very few groups will have patient cohorts that allow for a reasonable comparison. ${ }^{7}$ They analyzed the Ontario Health-related data, an administrative database through the Institute for Evaluative Sciences, and identified a cohort of 664 patients

From the Department of Cardiothoracic and Vascular Surgery, McGovern Medical School at UTHealth, Houston, Tex.

Disclosures: Dr Estrera is a consultant for W.L. Gore

Received for publication Dec 11, 2019; revisions received Dec 11, 2019; accepted for publication Dec 11, 2019; available ahead of print Jan 7, 2020.

Address for reprints: Anthony Estrera, MD, FACS, Department of Cardiothoracic and Vascular Surgery, McGovern Medical School at UTHealth, 6400 Fannin St, Ste. \#2850, Houston, TX 77030 (E-mail: Anthony.L.Estrera@uth.tmc.edu).

J Thorac Cardiovasc Surg 2021;161:530-1

$0022-5223 / \$ 36.00$

Copyright (c) 2020 by The American Association for Thoracic Surgery

https://doi.org/10.1016/j.jtcvs.2019.12.056

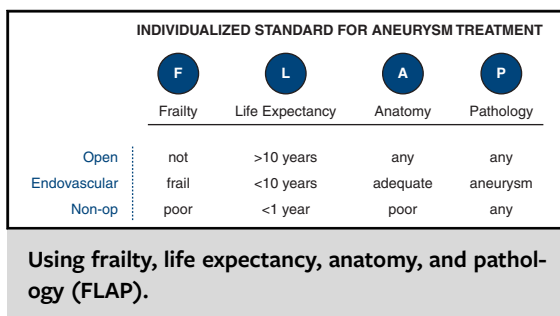

CENTRAL MESSAGE

As cardiovascular surgeons, we should not compete between open and endovascular when repairing thoracoabdominal aortic aneurysms but rather should always compete for what is best for the patient.

over an 11-year period. The data identified interventions based on standardized codes, excluding hybrid procedures and patient diagnoses from International Classification of Diseases codes. Appropriately, the authors reported composite outcomes of death, permanent paraplegia, stroke, and dialysis as thoracoabdominal aneurysm life-altering events. After propensity score matching (241 patched pairs), open repair was associated with greater in-hospital death $(17 \%$ vs $11 \%)$, thoracoabdominal aneurysm lifealtering events ( $26 \%$ vs $17 \%)$, and length of stay (12 vs 6 days) compared with endovascular. In the late term (at 8 years' follow-up), however, the early survival advantage seen in the endovascular group disappeared, and more reinterventions were noted in the endovascular group. The authors observed the sobering fact that patients with TAAA did not do as well when compared with the ageand sex-matched Canadian population in the late term.

Although much of the data reported here is not necessarily novel, it is still important in corroborating previous reports on the topic and confirming that TAAA remains a difficult disease to address. In light of this, there are a few points that require emphasis.

First, this was not a clinical database. It was an administrative database analyzed retrospectively and was subject to certain strengths and limitations worth noting. The strength included its ability to capture complete and reliable data on survival and reinterventions during the study period-a quality that challenges many retrospective cohort studies. The primary limitation, appropriately acknowledged by the authors, was related to the lack of more granular 
INDIVIDUALIZED STANDARD FOR ANEURYSM TREATMENT

\begin{tabular}{r:cccc} 
& Frailty & Life Expectancy & Anatomy & Pathology \\
\cline { 3 - 5 } Open & not & $>10$ years & any & any \\
Endovascular & frail & $<10$ years & adequate & aneurysm \\
Non-op & poor & $<1$ year & poor & any
\end{tabular}

FIGURE 1. Individualized standard for aneurysm treatment.

patient-related variables, such as TAAA extent, presence of dissection, and surgical technical factors-such as the use of adjuncts, cerebrospinal fluid drainage, etc-which are all important in predicting outcomes after TAAA repair.

Second, neither open nor endovascular approaches for TAAAs provide the perfect solution. Open repair is fraught with challenges with greater early mortality and morbidity, but endovascular treatment is associated with greater late reinterventions. Although not reported, it would have been interesting to see whether overall costs would have differed.

Third, thoracoabdominal aortic aneurysmal disease may be a systemic marker for overall atheromatous disease burden. Long-term survival was worse than the general population and neither approach, open or endovascular, provided a distinct advantage in the late period.

Fourth, patients with TAAA did better in centers with greater volumes (independent of type of repair) supporting regionalization of care for TAAA. The authors defined high volume as centers performing $>60$ cases during the 11-year study period (see Table E4 in their article). ${ }^{7}$ Interestingly, this would have been less than 6 cases per year to be defined as a high-volume center.

Finally, early outcomes improved with time both after open and endovascular. Although the comparisons were performed between open and endovascular, it was notable that early survival improved in the later period compared with the earlier period both with open $(22.4 \%$ down to $13.4 \%$ ) and endovascular (11.9\% to $10.0 \%)$. Although outcomes improve with greater experience, it was also likely that endovascular and open repair complemented each other, allowing for the patient to receive the most appropriate treatment.

Although this report provides important data corroborating other reports regarding the treatment of TAAAs, it still implies that there is a competition to be won: open versus endovascular. Unfortunately, we do this too often — suggesting one treatment is better than another, as opposed to emphasizing what is best for a specific patient in a specific situation ${ }^{8}$ (Figure 1). What we should remember is that differing treatment modalities may not necessarily be better or worse, just different.

Setting up a competition between modalities suggests that one is inferior-making us less likely to recommend it-as opposed to adopting it as another option for treatment. We should not think of this comparison as a competition of open versus endovascular but rather as complementary treatments, ie, open and endovascular. In the end, we are not competing for which is the best treatment modality but rather what is best for the patient. We should never forget for whom we are competing: the patient.

\section{References}

1. Estrera AL, Sandhu HK, Charlton-Ouw KM, Afifi RO, Azizzadeh A, Miller CC III, et al. A quarter century of organ protection in open thoracoabdominal repair. Ann Surg. 2015;262:660-8.

2. Coselli JS, LeMaire SA, Preventza O, de la Cruz KI, Cooley DA, Price MD, et al Outcomes of 3309 thoracoabdominal aortic aneurysm repairs. J Thorac Cardiovasc Surg. 2016;151:1323-37.

3. Coselli JS, Green SY, Price MD, Zhang Q, Preventza O, de la Cruz KI, et al. Spinal cord deficit after 1114 extent II open thoracoabdominal aortic aneurysm repairs. $J$ Thorac Cardiovasc Surg. February 12, 2019 [Epub ahead of print].

4. Oderich GS, Ribeiro M, Reis de Souza L, Hofer J, Wigham J, Cha S. Endovascular repair of thoracoabdominal aortic aneurysms using fenestrated and branched endografts. J Thorac Cardiovasc Surg. 2017;153:32-41.e7.

5. Arnaoutakis DJ, Scali ST, Beck AW, Kubilis P, Huber TS, Martin AJ, et al Comparative outcomes of open, hybrid, and fenestrated branched endovascular repair of extent II and III thoracoabdominal aortic aneurysms. J Vasc Surg. November 11, 2019 [Epub ahead of print].

6. Powell JT, Sweeting MJ, Ulug P, Blankensteijn JD, Lederle FA, Becquemin JP et al. EVAR-1, DREAM, OVER and ACE Trialists. Meta-analysis of individualpatient data from EVAR-1, DREAM, OVER and ACE trials comparing outcomes of endovascular or open repair for abdominal aortic aneurysm over 5 years. $\mathrm{Br} J$ Surg. 2017;104:166-78.

7. Rocha RV, Lindsay TF, Austin PC, Al-Omran M, Forbes TL, Lee DS, et al. Outcomes after endovascular versus open thoracoabdominal aortic aneurysm repair: a population-based study. J Thorac Cardiovasc Surg. 2021;161:516-27.e6.

8. Estrera AL. Is open repair still the standard for the descending and thoracoabdominal aorta? J Thorac Cardiovasc Surg. 2016;151:1232-4. 